\title{
Somatic embryos from callus of Salix viminalis $\mathrm{L}$.
}

\author{
L. Grönroos, S. von Arnold and T. Ericsson \\ Department of Physiological Botany, Uppsala University, Uppsala, Sweden
}

\section{Introduction}

This report is a summary of a manuscript which is in preparation and will be published elsewhere. Somatic embryogenesis in pistil callus of basket willow (Salix viminalis L.) is reported. Tissue culture techniques could become useful for breeding purposes if plants could be propagated via somatic embryogenesis. In order to facilitate identification of embryogenic callus obtained from Salix in the future, the embryogenic callus and the other callus types obtained are described morphologically, anatomically and ultrastructurally.

\section{Materials and Methods}

Floral buds of a female Salix viminalis $\mathrm{L}$. clone (78195) were collected during the non-growing season from field-grown plants provided by the Swedish Energy Forestry Project. The buds were surface-sterilized for $10-15 \mathrm{~min}$ in $7.5 \%$ calcium hypochlorite and rinsed in sterile water. After removal of the bud scales, the excised catkins were briefly covered with $70 \%$ ethanol and then rinsed 3 times in sterile water. Pistils were isolated from the catkins and cultured in darkness at $25^{\circ} \mathrm{C}$ on MS medium (Murashige and Skoog, 1962) containing $5 \mu \mathrm{M}$ 2,4-dichlorophenoxy-acetic acid and $0.05 \mu \mathrm{M}$ benzyladenine and solidified with $0.25 \%$ Gelrite gellan gum. The callus produced was subcultured every 3 wk. Different callus types were isolated from each other. Established calluses were transferred to hormone-free medium and cultured in dim light $\left(14-20 \mu \mathrm{E} \cdot \mathrm{m}^{-2} \cdot \mathrm{s}^{-1}\right)$. Somatic embryos produced were cultured on medium with $7.6 \mu \mathrm{M}$ abscisic acid (ABA).

\section{Results}

Calluses started to proliferate from the pistils within 2 wk. After ca 6 wk, 2 main types of calluses could be separated from each other.

Type 1 was a soft callus with a smooth wet-looking surface. It was composed of long, thin, tubular cells, single or attached end to end in rows, coiled or angled and interwoven and $10-50 \mu \mathrm{m}$ in diameter. The cells were highly vacuolated. Type 1 callus was non-organogenic.

Type 2 callus, which was rhizogenic, was composed of white or pale yellow, fast growing, friable, non-compact callus with an uneven surface as well as compact yellow nodules of different sizes. The proportions of friable callus and nodules varied. The nodules in type 2 callus were composed of tightly associated cells. The cells had rather large nuclei with prominent nucleoli and rather large vacuoles filled with electron absorbing material. The dense cytoplasm contained many starchfilled plastids with plastoglobuli, mitochon- 
dria, dictyosomes with vesicles, rough ER and a dense background of free ribosomes. Plasmodesmata connected adjacent cells. The friable type 2 callus consisted of large rounded cells, sometimes in aggregates and sometimes only loosely attached to each other. Most cells in the friable callus were highly vacuolated. The cytoplasm, which was pressed against the cell wall, was dense and contained numerous plastids with starch granules, mitochondria, dictyosomes with vesicles, rough ER and numerous polysomes. The friable type 2 callus also contained several less vacuolated cells and cell groups.

More than 6 mo after pistil isolation, type 2 callus produced type 3 callus, which was embryogenic. Type 3 callus was a friable, crumbly, bright yellow callus made up of small compact cell clumps. The cell clumps were composed of small densely cytoplasmic cells with large nuclei and prominent nucleoli. Many small vacuoles were scattered in the cytoplasm. The cytoplasm had a dense background of free ribosomes, numerous mitochondria and dictyosomes with vesicles, in addition to rough ER, microtubules, coated vesicles and multivesicular bodies. Plasmodesmata connected adjacent cells. Numerous amyloplasts containing one to several starch grains and some plastoglobuli were present. Type 3 callus has been maintained for more than $2 \mathrm{yr}$.

Somatic embryos were seen 1-2 wk after transfer of type 3 calluses to hormone-free medium as compact, smoothsurfaced, white to yellow globules or cupshaped structures. They soon acquired green glossy cotyledons with a tint of red towards the base, resembling zygotic embryos. However, many deviations from the normal development of zygotic embryos were also noted, for example, secondary embryo proliferation. Somatic embryos on medium containing $A B A$ ger- minated after transfer to hormone-free medium.

\section{Discussion and Conclusion}

The early identification and separation of different callus types from each other have greatly contributed to the maintenance of cereal cultures with high embryogenic potential (Tomes, 1985). Embryogenic callus from willow shared characteristic features with embryogenic cell suspensions of carrot (Halperin and Jensen, 1967; Wochok, 1973) and Pennisetum purpureum and Panicum maximum (Karlsson and Vasil, 1986).

The conversion of type 2 to embryogenic callus in willow has not yet been studied. The formation of embryogenic callus was unpredictable and difficult to manipulate. Research in this area is continuing.

\section{References}

Halperin W. \& Jensen W.A. (1967) Ultrastructural changes during growth and embryogenesis in carrot cell cultures. J. Uitrastruct. Res. 18, 428-443

Karlsson S.B. \& Vasil I.K. (1986) Morphology and ultrastructure of embryogenic cell suspension cultures of Panicum maximum (guinea grass) and Pennisetum purpureum (Napier grass). Am. J. Bot. 73, 894-901

Murashige T. \& Skoog F. (1962) A revised medium for rapid growth and bioassays with tobacco tissue cultures. Physiol. Plant. 15, 473497

Tomes D.T. (1985) Cell culture, somatic embryogenesis and plant regeneration in maize, rice, sorghum and millets. In: Cereal Tissue and Cell Culture. (Bright S.W.J. \& Jones M.G.K., eds.). Martinus Nijhoff/Dr. W. Junk, Dordrecht, pp. 175-203

Wochok Z.S. (1973) Microtubules and multivesicular bodies in cultured tissues of wild carrot: changes during transition from the undifferentiated to the embryogenic condition. Cytobios 7 , 87-95 